\section{Understanding knowledge translation in university-industry research projects: a case analysis in the automotive sector}

Knowledge translation in universities

\author{
Paolo Canonico
}

Department of Economics, Management, Institutions, University of Napoli Federico II, Napoli, Italy

Ernesto De Nito

Department of Economics and Statistics, University of Salerno, Fisciano, Italy

Vincenza Esposito

Department of Law, Economics, Management and Quantitative Methods, University of Sannio, Benevento, Italy

Mario Pezzillo Iacono

Department of Economics, University of Campania Luigi Vanvitelli, Capua, Italy, and Gianluigi Mangia

Department of Economics, Management, Institutions, University of Napoli Federico II, Napoli, Italy

\begin{abstract}
Purpose - In this paper, we depart from extant conceptualisations of knowledge translation mechanisms to examine projects as a way to achieve effective knowledge transfer. Our empirical analysis focused on a university-industry research project in the automotive industry.

Design/methodology/approach - The empirical analysis was based on a qualitative investigation. We analysed material collected within a research project involving a partnership between two universities and Fiat-Chrysler Automotive (FCA), a multi-brand auto manufacturer with a product range covering several different market segments. We used three data collection techniques: internal document analysis, participant observation and semi-structured interviews.

Findings - Our findings show that, in a U-I research project, goals represent a key dimension to support knowledge translation. Defining the goal implies an ongoing negotiation process, where researchers and company employees work together, in order to converge towards a shared meaning of the goal. In this sense, goal orientation and goal-based interaction have significant implications for knowledge translation processes. Originality/value - Studies to date have focussed on the concept of knowledge translation as a way to contextualise the transfer from the source of knowledge to the receiver and to interpret the knowledge to be
\end{abstract}

(C) Paolo Canonico, Ernesto De Nito, Vincenza Esposito, Mario Pezzillo Iacono and Gianluigi Mangia. Published by Emerald Publishing Limited. This article is published under the Creative Commons Attribution (CC BY 4.0) licence. Anyone may reproduce, distribute, translate and create derivative works of this article (for both commercial and non-commercial purposes), subject to full attribution to the original publication and authors. The full terms of this licence may be seen at http://creativecommons. org/licences/by/4.0/legalcode

Theauthors would liketo thank the guesteditors and the two anonymousreviewers for their generous and encouraging feedback, as well as the participants to the 14th International Forum on Knowledge Asset Dynamics (IFKAD2019) held in Matera, for helpful comments on an earlier version of this paper. The authors would also like to thank the management of thePratola Serra Plant-FCA, Italy,EMEA Region for invaluable support received at each stage of the research, and in particular thePlant Manager, Paolo Acastello, the Plant Quality Manager, Giuseppe Spina, the Plant HR Manager, Rosario Dell'Aversana, and all their teams.
Received 30 October 2019

Revised 3 May 2020 20 July 2020

Accepted 10 August 2020 
$\mathrm{MD}$

58,9

exchanged. This study expands the understanding of knowledge translation mechanisms in universityindustry research settings. It investigates the concept of projects as powerful knowledge translation mechanism in a dynamic and longitudinal perspective. Our contribution provides insight, reflecting on how the use of projects may represent a way to facilitate knowledge transfer and build up new ideas and solutions.

Keywords Knowledge translation mechanisms, Knowledge transfer, University-industry research project Paper type Research paper

\section{4}

\section{Introduction}

In recent years, universities have increasingly taken part in research projects involving firms. This is partly because of public expenditure policies that indirectly encouraged universityindustry (U-I) collaboration (Giuliani and Arza, 2009) to provide economic and social value. A lot of attention has been paid to interactions on the U-I interface, especially mechanisms able to facilitate knowledge transfer (Perkmann and Walsh, 2007). Empirical analysis has emphasised that knowledge transfer between universities and industry contributes to higher productivity and economic growth and examined the role of universities as a key driver for innovation (Bodas Freitas et al., 2014; Mueller, 2006).

In the U-I context, where knowledge is transferred across very different settings, knowledge needs to be translated to make it mutually understandable and relevant (Simeone et al., 2018; Graham et al., 2006). Knowledge translation is required to contextualise the transfer from the source of knowledge to the recipient and interpret the knowledge to be exchanged in a way that is meaningful for the recipient (Seaton, 2002). This understanding is an important addendum to the literature on knowledge transfer because it makes it possible to provide more thorough accounts on how to transfer knowledge in complex environments.

While knowledge transfer represents a traditional issue in the knowledge management field (Szulanski, 1996; Carlile and Rebentisch, 2003; Yih-Tong Sun and Scott, 2005), the concept of knowledge translation in management studies is relatively recent. Some authors (Simeone et al., 2017) have focussed their attention on the role of design as a way to facilitate knowledge translation, while others referred to the use of arts in management (Secundo et al., 2019a; Simeone et al., 2018). More traditional managerial instruments and tools deserve scholars' attention and should be investigated in order to understand their role in knowledge translation processes. This paper is focussed on the concept of project as a potential tool to foster knowledge translation.

Projects can be considered unique endeavours towards a common goal within a given duration (Lundin and Söderholm, 1995). Goals represent a fundamental issue in project-based coordination processes. "The explicitly stated, specific project goals are of great importance in enabling coordinated activity" (Lindkvist, 2005, p. 1201). Goals establish a common point of reference for the participants to interact across knowledge domains, envision a possible division of labour and negotiate on compromises (Lindkvist et al., 1998). Goals are typically identified as being the drivers to the delivery of joint outcomes involving interdisciplinary collaboration. More in detail, goals may have profound repercussions on the knowledge-translation outcomes.

This paper may therefore be located within emergent knowledge translation literature, in the effort to add to the understanding of project related mechanisms able to foster knowledge translation at the interface of U-I collaboration.

Our research questions may be formulated as: Do projects enhance knowledge translation in U-Icollaborations? How does theadoption of a common goalacross the various stages of a typical U-I research project may help in achieving effective knowledge translation in such contexts?

Our empirical analysis is located within a U-I research setting, carried out through a project organised as a publicly funded research contract in the automotive industry. This is a promising context to analyse the management of knowledge (Canonico et al., 2018) and a growing number of studies have emphasised the relevance of automotive R\&D linkages between universities and the industry to develop process and product innovation (e.g. Meng et al., 2019; Rasiah and Govindaraju, 2009). 
The remainder of this article is organised as follows. The next section reviews the literature on U-I research projects and knowledge translation, adding the idea of the project as a knowledge translation mechanism. The following section describes the research design and the methodology used for the empirical analysis. Finally, we present and discuss the findings before drawing conclusions.

\section{Background}

We build on the recent literature on knowledge translation in U-I research project to enrich the understanding of this phenomenon in a peculiar context. More specifically, our theoretical background draws on factors able to influence knowledge-translation processes (i.e. knowledge-translation mechanisms) in the context of U-I research projects, with the aim of sharpening the understanding of the project as a key mechanism to enhance knowledge translation. Therefore, we first proceed in shedding light on key features affecting knowledge translation in U-Iresearch project (par.2.1)and then analyse the characteristics of the projectas organizational arrangement, pointing out its contribution to knowledge translation (par. 2.2).

\subsection{U-I research projects: key features affecting knowledge translation}

U-I research projects have been studied from a variety of perspectives, including institutional dimensions of the collaboration, organisational culture, inter-organisational relations, intermediaries and brokerage able to facilitate such collaborations (Morandi, 2013).

Amabile et al. (2001) suggested that there are three important features of project collaborations between academic researchers and business practitioners. First, they involve people who are members of different professions (academia and business), second, they may be understood as collaborations between individuals or teams, not between organisations and third, the collaborators are not all members of the same organisation.

A significant part of organising these interdisciplinary research projects is the establishment of a shared language, relatedness of specialised knowledge, shared meanings, and ability to recognise the contribution of each individual knowledge domain (Kellogg et al., 2006).

Many scholars (Rajalo and Vadi, 2017; Schaeffer et al., 2020) investigated the issue of knowledge transfer as a key variable to get success in this kind of projects. Following Christensen (2003), knowledge transfer requires the identification of existing knowledge, the ability to acquire it and the subsequent application of such knowledge to develop new ideas. In the same vein, Simeone et al. (2017, p. 1409) stated that "the objective of a knowledge transfer process which takes place between two or more actors (individuals or organizations) is to enable an actor to acquire the knowledge of another actor".

A number of researchers have dealt with the interfaces of knowledge transfer among individuals engaged in inter-organisational collaborations across different domains of expertise (Simeone et al., 2018; Axelson and Richtner, 2017). Rajalo and Vadi (2017) studied the different practices adopted during the two main steps of a U-I project (initiation and implementation) to facilitate the management of knowledge. They adopted Rau et al.'s (2012) approach to define practices implemented to fill the gap between the partners to facilitate knowledge transfer. They described boundary-crossing and pragmatic boundary-crossing mechanisms as different practices used to facilitate communication and build a common framework among the partners. Collins and Evans (2007) examined the interactional conditions affecting knowledge flows in and across organisational borders. Specific forms of expertise play an important role in facilitating the coordination and transfer of knowledge across boundaries. When dealing with knowledge transfer at the interface of U-I research projects, Simeone et al. (2018) stated that, given the different objectives and languages prevalent in academic and industrial contexts, translation mechanisms between these two groups of stakeholders are needed to establish a 
common platform of communication and knowledge sharing, and "[. . .] there is still a lack of investigations about how to support the alignment and collaboration of different stakeholders, particularly in the context of academic entrepreneurship processes" (Simeone et al., 2018, p. 435). Knowledge translation becomes a (key) glue able foster knowledge transfer (Petrilli, 2003). Collaboration between heterogeneous actors from universities and industries often involves complex knowledge translation acts because each partner has his/her own nomenclature, demands and expectations of innovation (Sandberg et al., 2015).

In a U-I research project, translation is a dynamic process, where each actor operates at the organisational level to produce a specific output (a document, report, video, etc.). This involves adopting others' perspectives and selecting a framework and words that can be easily understood by others. It is therefore produced first at organisational level and negotiated and defined through collaboration (Secundo et al., 2019b).

One of the most critical factors in U-I research projects is the creation of an interactional space, where actors work together to overcome their individual and organisational interests and needs and to negotiate and collaborate to achieve a common goal. Creating this space is vitally important and may need specific effort: every player involved should his/her language to adopt a different framework, moving from his/her "natural environment" (De Rond and Bouchikhi, 2004). Universities often use a more scientific language, and the vocabulary can be hard to understand and share. Academics are used to publishing their work in scientific journals, each of which has its own style and rules for publication, including for language and references. Similarly, in industry, each organisation (or each organisational unit) uses its own language and has a particular way of storing and transferring knowledge.

In the knowledge-translation domain (Liyanage et al., 2009; Simeone et al., 2017), the idea of shedding light on the project as a knowledge translation mechanism is not analysed in depth, even if many studies are related to research contexts, in which project is an elective organizational arrangement.

\subsection{Project as a knowledge-translation mechanism}

Projects are able to engage with heterogeneous inputs from participants in order to foster knowledge translation. They allow the involved actors to clearly spell out their contribution towards a common endeavour. In this sense, they corroborate claims such as "this is what my knowledge means for you" (Seaton, 2002; Liyanage et al., 2009) rather than those resonating with putting in common bits of knowledge ("this is what I know so we can mutually integrate our knowledge").

In projects, participants need "good representations of what the others know [. . and] may thus, based on quite a minimalist base of shared knowledge, develop a pattern of interaction and the collective competence needed" (Lindkvist, 2005, p. 1200). The project may represent a guidance as to the knowledge needed to accomplish the goal, the feasibility of the solutions to be implemented within limits set as to the allocated resources. In our view, knowledge translation becomes then central in mutually clarifying knowledge inputs for the different participants in order to collectively act with a shared purpose.

In the management literature, projects are considered as a way to achieve novel objectives by reducing uncertainty (De Meyer et al., 2002). In many complex projects, problems emerge and are identified and solved by use of appropriate tools or through a web of interactions across organisational and disciplinary boundaries (Brown and Eisenhardt, 1995). Project management is therefore crucial to sustained problem-solving and understanding how activities in the project are organised and implemented. In the organisational-driven literature, management of projects requires consistent mechanisms over their lifetime.

Appropriate mechanisms are required to ensure that project activities are carried out, recognising existing interdependences. For instance, joint planning, task allocation, meetings and social structures all enable people to share and create organisational knowledge. 
Through standardisation, negotiations among participants and social interactions, projects therefore have full potential to be seen as the heart of the knowledge-translation process. Project teams have access to different knowledge bases but must also solve translation problems arising from multiple perspectives. In fact, at this interface, projects are entities that can provide for both complexity reduction and negotiation (Engwall, 2003).

Key project elements may have profound repercussions on the knowledge translation outcomes. Actors in the U-I projects are thrown away from their routine processes and structures to develop joint products, processes or solutions. Such separation may be of help for achieving the common effort and contribute to minimize obstacles to implementation of the collaborating entities engaged in a shared enterprise.

Goals push towards a mutual understanding, re-activate previous experiences and may be re-inforcing role-based coordination (Valentine and Edmondson, 2015). The temporal dimension is also obviously central in project-based reasoning because projects rely heavily on the use of the timeline as both a device to draw support and resources and for managing dispersed time orientations and local knowledge processes as time becomes a pervasive issue to prevent participants from being guided by concurrent orientations (Lindkvist et al., 1998, p. 948). Time constraint is also a form of control (Lindkvist et al., 1998) allowing for execution to proceed without external interference.

In sum, goal definition and time constraints represent two basic traits of the project as organizational arrangement, that are often critical in U-I research contexts and that can help in understanding knowledge translation outcomes.

However, projects account for specific knowledge translation mechanisms that may use both rationalistic tools and social interactions among participants. The first deals with conventional issues such as breaking the project into smaller components, ensuring careful planning, scheduling, estimating and execution of project tasks and striving for cost and time efficiency throughout the project to achieve the optimum outcome. To manage sources of uncertainty requires also close attention to interactional aspects. Managing meetings and deploying "soft" tools to enhance socialisation around technical issues (such as visualisation artefacts) may be crucial. There is a clear trade-off between reducing complexity of knowledge transfer through standardisation and more time-consuming issues of negotiations among participants requiring time and relationship-building (Engstrand and Enberg, 2020).

It is also useful to note that, within projects, focussing on planning, organizing, coordinating and controlling does not always fully reflect organizational reality as messy, ambiguous, fragmented and political in character (Hodgson and Cicmil, 2006). To this extent, widely accepted conventional views of the relationships between project and knowledge tend to underplay political and social processes pointing instead towards more simple issues and problems (Cicmil, 2006) that can be addressed through an appropriate corresponding action and behaviour.

\section{Research methods}

\subsection{Research context}

The empirical study was based on a qualitative investigation. We carried out the analysis iteratively with a semi-grounded approach, and our data informed the selection of theories (Van Maanen et al., 2007). We chose an example of a setting where project management was used in relation to the interplay of various stakeholders in a U-I collaboration (Eisenhardt, 1989). In line with the inductive approach adopted, we focussed on a single case study of particular interest rather than studying several cases (Yin, 1994). This should not be viewed as a limitation of our research, as shown by Cunningham et al. (2017), who conducted a review of qualitative studies in the field of knowledge transfer. The in-depth case study approach is advised when the boundaries between phenomenon and context are not entirely obvious, for example, the knowledge translation mechanisms used within a U-I partnership (Simeone
Knowledge translation in universities

1867 
et al., 2018; Dubois and Gadde, 2002). This is in line with Dyer and Wilkins (1991, p. 614), who advocated using a case study approach, and recommending that researchers should be aware of the benefits of "the careful study of a single case that leads [them] to see new theoretical relationships and question old ones".

We analysed empirical material collected within a research project involving a partnership between Fiat-Chrysler Automotive (FCA), a multi-brand auto manufacturer with a product range across different market segments and two universities, the University of Sannio (Department of Management, Italy) and Portsmouth Business School (Department of Operations and System Management, UK). The project's main aim was to develop and implement a multi-criteria method to modify the quality control cycle of assembly-line production. The researchers from the two universities had different and complementary expertise in innovation management. The Portsmouth researchers had expertise on topics such as data envelopment analysis and multi-criteria decision-making. The Italian researchers had skills in organisational design and human resource management. The project was funded by the National Operative Programme FSE-FESR Research and Innovation, Action 1 - "Dottorati Innovativi con caratterizzazione industriale".

At the time of drafting this case study, the project (formally presented in December 2017) was in an intermediate stage (October 2018-July 2019). It followed the decision of the Italian Ministry of Education, University and Research to finance the project activities for a threeyear period and was at the end of the third project phase (see Table 1).

The case selection phase used two main criteria. First, the specific FCA plant with which the partnership has developed shows the adoption of knowledge management methods and tools as enablers for the development of process and product innovation (Canonico et al., 2018). This study used empirical material collected at FCA's Pratola Serra Plant, in Avellino, Italy. The Pratola Serra Plant was founded in 1991 and has received many certifications and awards, but it has also experienced some problems and important organisational changes. From a performance perspective, it moved from producing 570,000 engines in 2007 to 170,000 in 2015, back to 300,000 in 2016. Recent trends and forecasts are encouraging enough to think this figure may increase again. Recently, FCA has refined the organisational design at the plant using the Work Place Integration initiative, a broad program of activities designed to streamline manufacturing processes, using a lean product development approach.

Second, as is common in literature, we selected a case study in which the phenomena of interest - in this case, the use of knowledge translation mechanisms in a U-I project setting were transparently observable. The case study provided a consistent, differentiated and information-rich setting for studying the phenomenon of knowledge translation. One of the authors of this paper was also directly involved in the project team.

\subsection{Data collection}

We used three data collection techniques: internal document analysis, participant observation and semi-structured interviews. Documentary analysis enabled an understanding of the project structure and tools (for example, flow diagram, GANTT charts, budget, work breakdown structure scheduling, and diagrams). Participant observation was used to explore knowledge translation issues among the different partners of the project. During her fieldwork, the third author spent from 8 a.m. to 2 p.m. in the Plant for one to two days a week during alternate weeks. Having free access to the Plant premises, she was able to make numerous formal and informal contacts and become relatively familiar with the management. Finally, in-depth interviews with the management of FCA were the main source of data for this study. Five semi-structured interviews were conducted with the world class manufacturing Plant coordinator, the Pratola Serra Plant manager, the Plant HRM manager, a manufacturing engineering manager, the Plant quality manager and the Portsmouth expert in data mining and multi-criteria decision-making. 


\begin{tabular}{ll}
\hline Phase & Activity \\
\hline $\begin{array}{l}\text { Phase 1-Project } \\
\text { planning }\end{array}$ & $\begin{array}{l}\text { Creation of a comprehensive } \\
\text { suite of project plans that } \\
\text { set out the project roadmap } \\
\text { and showed plans to } \\
\text { manage time, cost, quality, } \\
\text { change, risk and issues } \\
\text { (necessary for public } \\
\text { funding) }\end{array}$
\end{tabular}

TOOL/artefact of

Participants knowledge translation

(1) Ministry of education, university and research (delegated official) (2) Two FCA managers (quality and operation managers)

(3) Four management researchers (university of sannio)

(4) A researcher from university of portsmouth

Phase 2-Project Monitoring, analysis and launch

Phase 3 Building the new multi-criteria decision-making method reporting of anomalies in the engine assembly process (i.e. prioritizing errors)

Creating and experimenting with research hypotheses: the application of multicriteria decision analysis methods (and solving decision problem) into engine assembly process (e.g. building the portfolio of critical processes)
(1) Project template (submission form) and project charter

(2) Flow diagram

\section{(3) GANTT chart}

(4) Budgetary control

(5) Work breakdown

structure

(6) Fishbone diagram

(7) Call for proposals

Frequently Asked

Questions

A team composed of four university researchers (university of Sannio) and four company managers platform) schema presenting the anomalies instructions researchers

An "empowered" team of two FCA engineers, two researchers from the University of Sannio and another from the etc.)
Knowledge translation in universities

1869

(8) Formal and informal cross-boundary meetings

(1) Project management software (a cloud-based

(2) Visual formats: visual diagrams and a graphical

(3) Mandatory reporting

(4) Face-to-face interaction between managers and University of Portsmouth (1) Visual collaborative environment (projector, screens, pictures, graphs,

(2) Virtual management: visual diagram and visual design tools for the simultaneous communication between people located in the same physical space and/or different sites (Italy and UK)

(3) Intermediate report

(4) Face-to-face interaction and negotiations between managers and researchers
Table 1.

Tools and artefacts adopted to translate knowledge

Each interview was conducted by at least two authors of this paper to reduce interviewer bias (such as first-impression error, non-verbal influences or negative emphasis). The interviews were based on an open, wide-ranging protocol (Czarniaswka, 2004), provided one week before the first interview. This invited the interviewees to explain how they had worked in the different stages of the research project. The interviews were guided by a questionnaire including questions about (see Appendix): 
$\mathrm{MD}$

58,9

1870

(1) The overall organisation of the project (for example, in how many phases was the project articulated? Could you describe the main objectives, working methods and critical points of each phase? What were your main tasks?).

(2) Organisational practices within the cross-boundary team (What were the main coordination mechanisms used among project members? Could you describe an episode where there was a misunderstanding between researchers and managers? Can you describe a specific incident? What actually happened? Can you provide an example of a problem that you solved and how? How was the meeting space used? How frequently were formal or virtual meetings held to discuss new ideas or process upgrading? How was project management software used?).

(3) Knowledge management mechanisms and practices (What were the main tools to exchange data, information and knowledge between project members at different phases of the project? How were those tools actually used? What kind of knowledge did you need to work effectively?).

The protocol aimed to stimulate interviewees' interest in this participative research process and to promote a narrative approach, crucial for the success of the interviews. The collection of data was carried out between October 2018 and early May 2019.

\subsection{Data analysis}

Our analysis was in stages. The interviews were taped and roughly analysed, and we wrote memos to coordinate and develop a common view among the authors. In the second step, all five authors listened to the recordings. We compared the raw material and the written notes taken during the interviews with the recordings. The personal involvement of one of the authors in the research project allowed us to inquire into the process of knowledge translation from the inside (Evered and Louis, 2001).

We first listened to all the interviews to understand the general ideas expressed. We then reviewed the recordings, transcribing the interviews verbatim, stopping the recording after every sentence, to be sure that the meaning was clear. We did this immediately after recording and read the transcripts several times. Sections dealing with the practices, tools and artefacts used for knowledge transfer during the different stages of the project were noted. This reminded us of the events, words and looks and helped us to remember what happened in each interview. Most of the conversations during interviews were not spontaneous, but we were interested in showing the managers' and practitioners' voices and attitudes, to enable readers to experience the interviews more effectively. We also used a triangulation strategy, comparing the evidence from different sources (interviews, participant observation and formal sources). In the final step, we used the interviews as texts, with knowledge translation theory as a guide. We sought to understand the most frequent affirmations about cross-boundary interactions, project tools (e.g. project template, project charter, diagrams and virtual design tools), formal and informal coordination mechanisms and procedural and routine patterns. This provided the 'text' for interpretation. The data were therefore interpreted by identifying how the translation process was developed using the set of project management methods and practices.

\section{Case analysis}

The U-I research project aimed to test mathematical models of multi-criteria analysis to support organisational control functions in the automotive sector. The project proposed the use of methods to allow a more conscious weighting of the factors that determine organisational performance, favouring organisational development, innovation and the 
enhancement of human capital. The universities and the company carried out different types of activities in the execution of the research project. These activities were grouped into three distinct phases: project planning; project launch and building the multi-criteria decisionmaking method. Table 1 summarises the different project phases, showing the main activities, participants and artefacts and tools used to translate knowledge in each phase.

\subsection{Project planning}

The most common coordination solution in the early stage of the project planning phase was methods and practices devised by the partners. They largely focussed on communication and direct comparisons between partners. During a series of meetings, the theoretical and operational perspectives of the study were discussed and defined. The expected goals and outputs were negotiated, and the investigation methodology was developed.

Afterwards, in the definition of the project proposal, the comparison between the partners was channelled into a formal path as the project documentation was drafted. An important role was played by formal evaluation and funding tools (project template, flow diagram, GANTT charts, timeline, budgetary control, work breakdown structure scheduling, status table and fishbone diagram). The template for the project (which must be followed to obtain public funding) had been a part of similar previous tenders. This constituted the main frame in the implementation of this phase. Following the guidelines to make the work eligible and attractive for funding meant explaining the research in "project language", setting out responsibilities, resource allocation, work packages and reporting structures. These were all central components in the toolbox and had to be included so that the application would pass the first component of the assessment process. The standardised forms for planning purposes were a way to specify and control the content to be shared among project members. This gave structure to the discussions in the project meetings.

\subsection{Project launch}

After the positive evaluation by the Ministry and obtaining three-year funding for the proposed activities, the group of four university researchers and four company managers carried out a series of meetings and contacts to define the details of the first activities in the project. In this phase, project management software was adopted: a cloud-based platform that allows users to gather ideas, execute tasks, track progress and ultimately achieve goals. The team members started to use this app for project activities like sharing documents and signing off plans.

Two meetings were held at the manufacturing plant to present the project to the employees involved in the work processes studied and to discuss the selection and data collection criteria for the start-up phase of the theoretical decisions model. The Plant Director stated in an interview:

From the beginning, I proposed to choose, as a focus of the research study, the problem of the evaluation of improvement actions that could be designed periodically, after the detection of anomalies during engine assembly. After a long chat with the two professors and the sharing of a visual diagram (a graphical schema presenting error prioritisation) ... I became aware of the need to modify our system of classification and evaluation of anomalies during the assembly phase ... The process by which academics and engineers acquired a mutual perception of each other's needs in the development of the project was far from easy.

Engineers and academics analysed the sequential patterns of the control processes, and the existing organisational procedures and routines were identified and mapped. After four months of work, the project group had completed the monitoring of the anomalies that emerged in the engine assembly process. 


\subsection{Building the new multi-criteria decision-making method}

In the third phase of the collaboration project between the company and the university, the main effort was dedicated to transferring, understanding and interpreting existing decision-making models in a common form. It was decided to set up a working team from the existing project group, composed of two engineers, two researchers from the University of Sanni and a researcher from the University of Portsmouth. This team was tasked with achieving a radical change in the anomaly analysis decision model and collecting all the data sets from the last two production cycles for the transfer to Portsmouth. It was also decided that one of the Italian researchers would participate in the testing phases at that university.

This team worked together in a specific space at the Plant, where academics and practitioners interacted and collaborated using interactive tools, especially for visualisation. The team's work was enabled by a large-scale visualisation of content and personalised desktop views. The room integrated physical spaces and virtual tools in a visual collaborative environment that supported co-located Italian team members and the UK-based researcher in tight synchronous collaboration. The manufacturing engineering manager commented:

The visualisation of technical data increases awareness of the design and drawings among all those involved. The use of pictures, graphs and colours makes it possible to grasp complex relationships between many different factors very quickly ... Visualisation helped to support fruitful communication and decision-making processes, [and] strengthen the intermediate goals of our work ....

\section{Knowledge-translation practices and mechanisms}

Two knowledge translation episodes were particularly significant for knowledge transfer between the different organisational actors involved in the project. These are illustrated below.

The two translation episodes refer to two specific decisions identified in phases 2 and 3 of the project. They were indicated by most of the interviewees as particularly important and representative "incident cases" in the definition of specific sub-goals of the project. Furthermore, also the author who conducted the "participating observation" activity highlighted how both the "prioritising errors" and the "building the portfolio of critical processes" are two crucial and evident episodes in which specific knowledge translation practices, mechanisms and artefacts facilitated knowledge transfer between researchers and practitioners.

\subsection{Prioritising errors}

In the project launch phase, the specifications for the quality control model were defined. In this phase, an event of particular importance was likely to become a highly critical factor. The model proposed by the researchers used the application of the multi-criteria logic to analyse errors made by the workers during the assembly of the engine. The model, among other things, was intended to classify the errors by level of importance.

FCA already had a system for the analysis of error prioritisation. The system was based on WCM protocols that were adopted by all the companies in the automotive group. A frame called the QA Matrix identified anomalies related to the production process and located them to the phase in which they were generated, providing an index of priority that was the result of different weights given to the frequency of the error, the costs generated, the detection methods and the severity. At the time of the development of the first part of the new model, the company managers involved in the project were neither interested nor available for this type of experimentation. The quality manager asserted: 
We have invested heavily in training and WCM-inspired management systems in recent years. Our error prioritisation system allows us to "weigh" errors detected in the assembly line using the four most important criteria for evaluating the performance of the manufacturing process.

The multi-criteria decision making expert commented:

I thought I couldn't convince them! The quality manager stubbornly and repeatedly stressed the lack of interest in experimenting with a different way of classifying production anomalies. Beyond the need to complete my experimental research, I couldn't accept not being able to understand the limits of that error classification approach. Their classification criteria were based on an algorithm similar to that of the average of four variables and did not lead to an accurate analysis of the observed phenomena.

The working group had four working sessions on this topic. In the third of these sessions, the use of a visual diagram made by the academics proved to be an unexpected turning point (see Figure 1). The visual representation (a visual translation) of the methodological advances termed the glasses of wine - showed the weaknesses of the existing error prioritisation method based on boolean logic (weakness a. No definition of weights; b. Aggregation of criteria) and intuitively illustrated the main advantages of the multi-criteria method (based on a fuzzy logic). The diagram was accompanied by a series of sketches made with an electronic pen by mathematicians.

As a result of this presentation, the working group as a whole became more aware of the proposal made by the university partners. The new multi-criteria method made it possible to assign priority indices to assembly errors, evaluating anomalies more precisely without losing valuable information, the weakness of average-based algorithms. The last of the four work sessions followed a series of chats and interim reports exchanged through the shared project management software platform. It was attended partly in person and partly remotely, through videoconferencing.
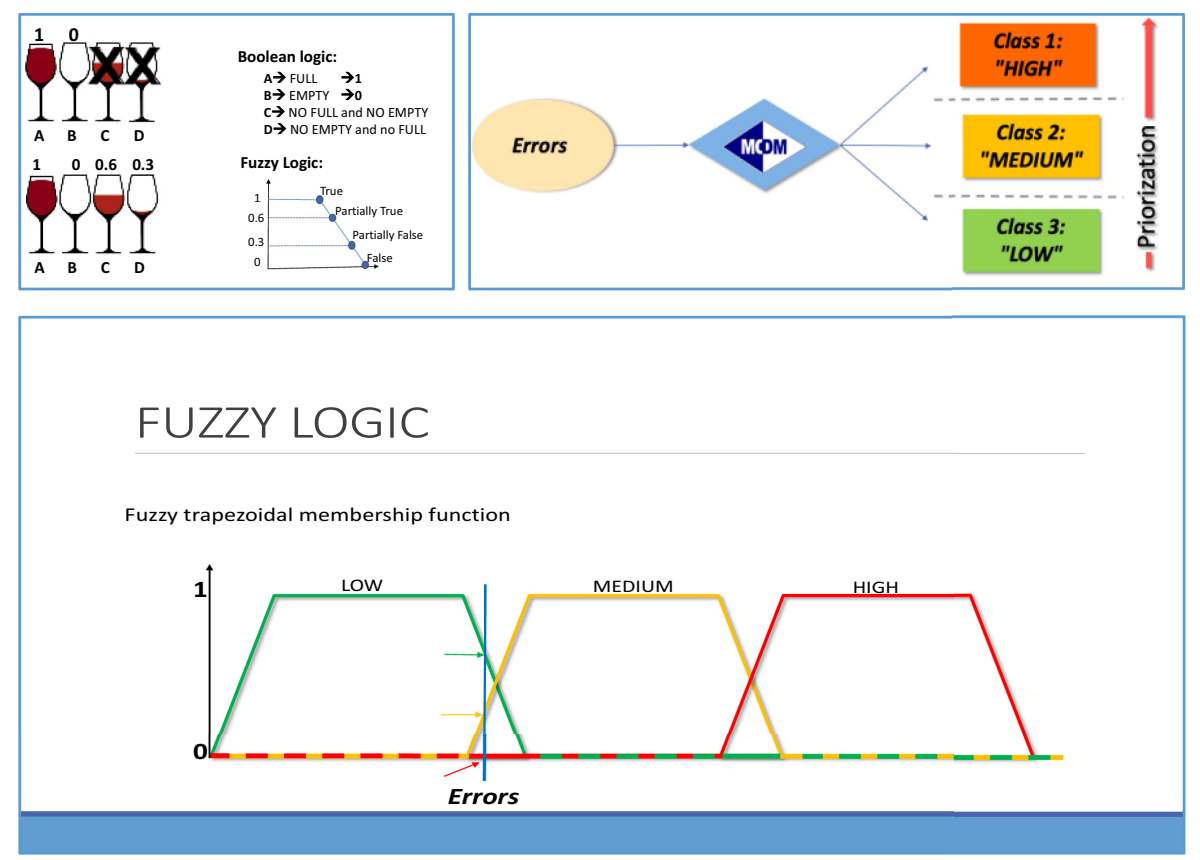

Figure 1.

The glasses of wine diagrams

Knowledge
translation in universities 
The group closed the session by deciding to adopt the new multi-criteria model for error prioritisation but also planned to work in the next testing phase to better define weighting standards. The organisational academic stated:

The time and energy spent in the dialogue together with the intuition of elaborating "the diagram of the glasses" was the real foundation for our ability to understand each other. The glasses and the image of the trapeziums seemed to be "magic keys" to open a new channel of communication. The company understood the richness of the analysis we proposed and we understood the criticality of changing a practice that affected the evaluation of people's mistakes on the assembly line. Now that we are in the experimental application phase, it is as if we had a new common subject to shape!.

\subsection{Building the portfolio of critical processes}

A second critical episode in terms of communication and comparison between the project partners emerged when the forms of experimentation around the new quality control model (phase three of the project) had to be defined. After reaching an agreement on the "prioritisation" of anomalies, academics and managers addressed the issue of identifying organisational improvement actions capable of reducing errors in the assembly process.

It took two weeks of activity during which three meetings were scheduled. The academic partners proposed applying the multi-criteria logic to the evaluation of alternative organisational development actions. The company already had a consolidated methodology but was willing to develop a more effective one within the general rules of the WCM system. The existing method was based on the concept of "critical process": in practice, on the idea of modifying the part of the process in which serious anomalies most often occurred. The concept of "critical process" was new to the academics, or at least not entirely clear compared to the field of applications that had already been tested in other research projects. The project team therefore initiated a discussion about the possibility of using multi-criteria analysis as a basis for decision-making for organisational change, adapting the model to the WCM pillars.

The possibility of visualising a decision-making grid (DMG) method during group meetings significantly facilitated comparison between the positions of managers and academics. This generated a new convergence of ideas on the concept of "critical process". Through the matrix, it was possible to identify "pieces" of the process, distinguished in green, yellow and red (see Figure 2). The production engineers made short videos (attached to the platform) to show which assembly activities corresponded to those different "pieces".

Figure 2.

The decision making grid

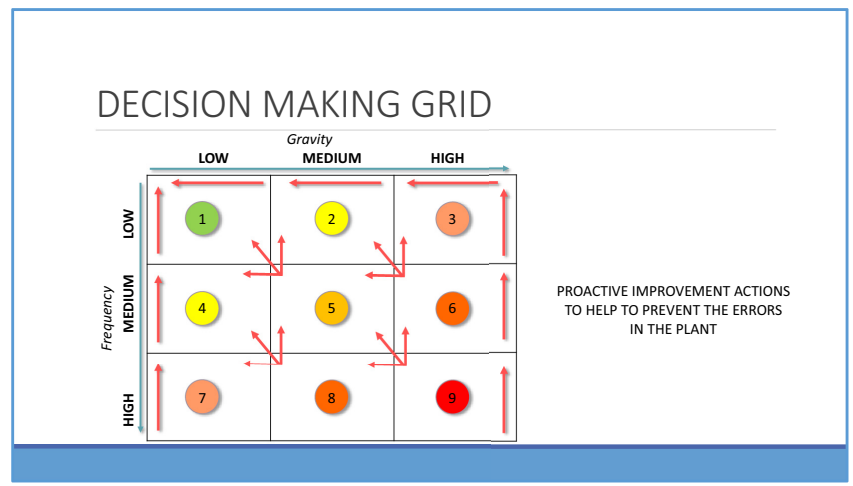


Using this method, the project team generated an original way of researching the process in which to invest in quality improvement. Rather than identifying the process in which errors occurred most frequently, they identified processes in which re-design interventions could be carried out (even in parallel), and where the effects could be effectively evaluated. The project team had therefore identified a new concept of critical process: from a process in which more serious errors occurred, to a process where the company could intervene with greater benefits, selecting the nature of the benefits (for example, economic, employee safety, implementation time or economies of scale).

At the end of the discussion at the last meeting, the mathematical decision-maker said:

I am pleased that one of the most powerful properties of multi-criteria methods has emerged, namely the possibility of considering a diverse set of criteria at the same time and involving the decision maker more closely in the choice of improvement. This application opens new horizons for future research activities.

Even the quality manager recognised:

With the multi-criteria approach to error analysis, we are no longer looking for a unique and optimising result, but trying to identify the elements useful to clarify the priorities on which to base the choices [...] even if this does increase and aggravate the level of participation and responsibility of the manager in the analysis of alternatives.

The organisational academic added:

I think we have achieved an additional advantage ... Having developed the concept of a "sensitive process" together, the DMG method will allow us to build a portfolio of processes on which to focus investment ... and in the subsequent testing phase, we will strengthen this perspective!.

\section{Discussion}

Using the concept of knowledge translation introduced in the theoretical section, here we discuss the project as a dynamic process able to foster knowledge translation (Liyanage et al., 2009).

In our case, the knowledge translation process and aims were peculiar because, unlike other contributions (Lenfle and Soderlund, 2019; Simeone et al., 2017; Bogers and Horst, 2013; Petrilli, 2003), there was no attempt to set up a universal language that could be easily understood by different players and communities. In our case, the knowledge to be made common was academic and scientific knowledge on one side and empirical and practical knowledge on the other.

This is not necessarily easier than the first approach, only different. Theoretical sections made clear that universities and industry have different languages and styles and individuals may fall into the trap of thinking that their knowledge is "correct" (De Rond and Bouchikhi, 2004). This makes it harder to understand another point of view (Sandberg et al., 2015). Each person is knowledgeable about specific tools and methods and is often suspicious of other perspectives.

The aim of this section is to discuss how the project could be interpreted as a locus where formal and informal elements make translation possible and "easier" to realise (Lenfle and Söderlund, 2019). It considers the way in which projects act as an effective knowledge translation mechanism at the interface of a U-I research context. It also reflects on specific project tools and how they affect knowledge translation in U-I research project.

The first issue concerns a more general approach to knowledge translation: projects, typically involving interdisciplinary collaboration, are environments where participants work jointly to create common knowledge and achieve a mutual goal (Axelson and Richtner, 2017; Valentine and Edmondson, 2015). Following this argument, and in line with the project

\section{Knowledge translation in universities}

1875 
management literature (Soderlund and Tell, 2011), we believe that defining and sharing the same goal is the first and (maybe) most complex issue in a project (Lindkvist, 2005; Engwall, 2003). It could appear simple to define a specific aim and then work together, but our case shows how difficult it can be in practice, especially in a U-I collaboration (Rajalo and Vadi, 2017; Morandi, 2013). Industry is typically driven by financial returns and considers research projects as a way to implement new knowledge and to improve performance (Bruneel et al., 2010). Universities, however, have a broader mission in terms of research outcomes and societal impact (Giuliani and Arza, 2009). Defining a common goal requires combining these two different aims. Our case analysis shows that defining the goal is not enough. It is not a static decision, but an ongoing negotiation process. As researchers and company employees work together, they redefine the meaning of the goal.

The conventional iron triangle (Atkinson, 1999) is also important: academics and company employees need to consider time, quality and cost restraints. These constraints have a considerable influence on how people work. The formal part of a project includes planning, scheduling and controlling activities. The use of project tools allows partners to facilitate planning and control (Canonico and Söderlund, 2010). The creation of the deliverables and work breakdown structure facilitates planning and monitoring of progress. It also helps to break down major deliverables to tasks in work packages. The effects of project changes are documented and traceable. Timelines, responsibilities, resource allocation, work packages, reporting structures and budgets are therefore all central components of the toolbox. These tools must be addressed for a funding application to receive approval: they can facilitate the translation of coded activities across existing boundaries, help to resolve conflicts and facilitate individuals' sense of mutual accountability (Lainer-Vos, 2013). Deadlines (time pressure) force people to find a solution. They often pass through a different and shared way of interpreting a specific phenomenon. Previous studies have acknowledged the process and dynamic nature of projects and investigated time pressure, trust-building, problem-solving, sense-making and learning dimensions. These have, for example, been used in analysing the nature and process of the behaviour of projects (Soderlund, 2011).

In our view, it is the project (both its cultural values and specific constraints and tools) that helps the knowledge-translation process. It is a long and complex process that is closely related to the project life, not a single moment where translation takes place. It may therefore be better to refer to the concept of knowledge translating, clarifying the dynamic and process view (Simeone et al., 2017).

The project can therefore be interpreted as the interactional space where different players share the framework and develop a common language (the language used in the reports, budget and all the tools related to the project). The project pushes participants to adopt formats and languages that in turn become shared assets of the collaboration. This means that both projects, as coordination mechanisms, and project tools themselves have the potential to become a fruitful interactional space where participants may effectively enhance knowledge translation (Scandura, 2016).

If projects in general can be interpreted as a way to facilitate knowledge translation, our critical episodes show something more. Knowledge translation can be considered as a dynamic process of interpretation and negotiation (Simeone et al., 2018). The two episodes described show how some specific moments during this project were key in fostering knowledge translation. For example, the "glasses of wine" diagram could be considered as a tool that was essential to obtaining a shared understanding of the limitations of the error prioritisation model. What came before and after was fundamental to reading the diagram, but the diagram itself was the key. It seems likely that sharing the same diagram at a different time would not have had the same result. Translation was only possible because of a combination of different social factors. 
The project goal may play an important role in this (see Table 2). In this case, at the beginning of the project, the firm did not want to modify its models. The company had invested heavily in internal training and defining managerial decision support systems before the launch of the collaboration project. This was perhaps why a unidirectional representation and transfer of the theoretical and methodological construct already available in FCA seemed to dominate the early phases of the project. In those phases, the company's objective - in part, formally declared in the project - seemed to be a marginal increase in the potential effectiveness of the management control tools already provided by its quality management system. The academics wanted a new opportunity to test their model and hypothesis, without considering the real opportunities and the practical implications of their approach.

In the third phase, the types of activities carried out, but especially the way in which these were interpreted by the company, seemed to signal a change in the company's attitude towards knowledge transfer. Strengthened by its internal organisational capacity to manage knowledge transfer processes for organisational development, the company showed commitment and attention by granting the university partners a more autonomous role in recombining knowledge on typical problems in production and managerial processes. After considerable discussions and hard work, the firm representatives changed their mind. The university researchers also understood that there was an opportunity linked to the theoretical approach.

Goal orientation and goal-based interaction have significant implications for knowledgetranslation processes. In heterogeneous inter-organizational coordination projects (such as U-I research projects) encourage what Grabher defines as "situative pragmatism" (Grabher, 2004, p. 1492), whereby knowledge becomes useful towards the common task and overall performative outcome of the projects rather than towards a mutual establishment of a common knowledge ground.

The two episodes analysed were crucial because in each one, the players involved defined a new common language and a new common goal. Translating knowledge became an opportunity to modify a specific and single goal to define a new common objective: to create a new model that could be adopted in line with the WCM and maybe in the future become a start-up (acting as consultant firm in the prioritisation field). They therefore show the idea of the project as boundary-spanning process, which is crucial in multi-disciplinary settings to deal with differentiated knowledge and expertise (Canonico et al., 2017). Instead of erecting

\begin{tabular}{|c|c|c|c|c|}
\hline $\begin{array}{l}\text { Critical } \\
\text { episodes of } \\
\text { knowledge } \\
\text { translation }\end{array}$ & Tool & $\begin{array}{l}\text { University's } \\
\text { goal (before the } \\
\text { critical } \\
\text { episodes) }\end{array}$ & $\begin{array}{l}\text { Firm's goal (before the } \\
\text { critical episodes) }\end{array}$ & $\begin{array}{l}\text { Common goal (after the } \\
\text { critical episodes) }\end{array}$ \\
\hline $\begin{array}{l}\text { Prioritizing } \\
\text { errors }\end{array}$ & $\begin{array}{l}\text { The visual } \\
\text { representation of } \\
\text { "the glasses of } \\
\text { wine" }\end{array}$ & $\begin{array}{l}\text { Verifying the } \\
\text { validity of the } \\
\text { model }\end{array}$ & $\begin{array}{l}\text { FCA already had a } \\
\text { system for error } \\
\text { prioritisation. The goal } \\
\text { was to improve this } \\
\text { model }\end{array}$ & $\begin{array}{l}\text { The group closed the } \\
\text { session by deciding to } \\
\text { adopt the new multi- } \\
\text { criteria model for error } \\
\text { prioritisation }\end{array}$ \\
\hline $\begin{array}{l}\text { Building the } \\
\text { portfolio of } \\
\text { critical } \\
\text { processes }\end{array}$ & $\begin{array}{l}\text { The decision- } \\
\text { making grid }\end{array}$ & $\begin{array}{l}\text { Applying multi- } \\
\text { criteria logic }\end{array}$ & $\begin{array}{l}\text { Developing a more } \\
\text { effective way of } \\
\text { reducing errors in the } \\
\text { assembly process } \\
\text { within the general rules } \\
\text { of the WCM system }\end{array}$ & $\begin{array}{l}\text { The project team } \\
\text { generated a new and } \\
\text { original way to } \\
\text { research the process to } \\
\text { use to decide how to } \\
\text { invest in quality } \\
\text { improvement }\end{array}$ \\
\hline
\end{tabular}

Knowledge translation in universities

1877 
and codifying a communal knowledge base, knowledge translation allow the interaction to be fruitful while being driven by the common goal, even if the different knowledge bases keep staying well apart.

In summary, we have showed that in this case, the project itself acted as a knowledge translation mechanism. The project was a long process, and critical episodes had major effects on the entire structure. Both these factors (the ongoing process and the critical episodes) were crucial for translating knowledge.

\section{Concluding remarks}

The main objective of this paper was to understand if and how, as part of a specific U-I collaboration initiative in the automotive sector, projects can be interpreted as a mechanism for translating knowledge. This context is unique because of the specific features of those involved.

The automotive industry is an interesting case for the analysis of knowledge transfer (Valio Dominguez Gonzalez and Fernando Martins, 2014). Over the past two decades, this sector has undergone a radical transformation, with several basic structural changes, which have affected the scope of the market, the new competition regimes and the new ways of organizing production across borders. Inter-organizational relationships "hand in glove" have changed, due to modularization and outsourcing (Furlan et al., 2014), and R\&D collaborative initiatives between universities and industry have become increasingly important to develop the process and product innovation (Meng et al., 2019; Rasiah and Govindaraju, 2009). Furthermore, most car manufacturers have experimented with various organizational models for production, trying to move from the Fordist approach to more modern models and practices, such as knowledge management and project management (Canonico et al., 2020; Cabigiosu and Camuffo, 2012).

In particular, the management of inter-organizational projects for the launch and production of new vehicles has become more complex to face these new challenges.

This makes the study of knowledge-transfer processes between the different project partners crucial, and, consequently, the analysis of the knowledge-translation mechanisms, practices and artefacts that facilitate knowledge transfer very relevant.

Our empirical findings showed why and how projects should be used to foster knowledge translation in this kind of setting. First, projects are an environment where different constraints affect how people are involved and participate in the development of the project. The impact is mainly through culture and how the project is run. In particular, our results show how different organisations come together to define new meanings and solutions and so change the goal of the project. Thanks to the knowledge translation process, players see both new meanings and new opportunities to exploit.

The existence of specific critical episodes is also a way to define knowledge translation. It is interesting to reflect on the relationships between a specific time and the life of the project. Critical episodes are specific times when knowledge translation takes place, but they are closely related to what happened before and influence what happens in the future. In this sense, therefore, even if you look at a specific time, you also need a longitudinal approach. This idea is a way to confirm the dynamic view of knowledge translation. We can only truly understand translation and how it occurs by seeing it in the context of the overall project.

From a theoretical perspective, our paper expanded the understanding of knowledge translation mechanisms in university-industry research settings in two respects. First, it investigated the concept of projects as powerful knowledge translation mechanism in a dynamic and longitudinal perspective, especially in a U-I setting. Our contribution therefore provides a useful insight, reflecting on how the use of projects is a way to facilitate knowledge transfer and build up new ideas and solutions. 
Secondly, our paper explores how the adoption of a common goal across the various stages of a typical U-I research project may help in achieving effective knowledge translation in such contexts.

The study was exploratory. It may therefore be useful in generating research hypotheses in future work, particularly connecting the features of interdisciplinary projects with the development of knowledge-translation mechanisms.

From an empirical point of view, our results may be useful for other firms operating in the same sector and for policymakers wishing to stimulate this industry. We suggest that emphasising the project approach may facilitate knowledge translation. This choice could lead to new opportunities during the project life.

This study also had some limitations, which must be taken into account when evaluating its results. First, the study used a qualitative approach, so its results may not be generalisable more widely. However, this approach was consistent with the study objectives and the nature of the research question. It allowed us to draw insights that may be important in advancing theory. Second, the case study was set in a specific context that conditions our concluding remarks. Future studies should address how knowledge translation can be achieved. Finally, it would be helpful to analyse in more depth how the coordination mechanisms used in each phase of the research project actually influenced outcomes, in terms of knowledge translation.

\section{References}

Amabile, T.M., Patterson, C., Mueller, J., Wojcik, T., Odomirok, P.W., Marsh, M. and Kramer, S.J. (2001), "Academic-practitioner collaboration in management research: a case of cross-profession collaboration”, The Academy of Management Journal, Vol. 44 No. 2, pp. 418-431, April 2001.

Atkinson, R. (1999), "Project management: cost, time and quality, two best guesses and a phenomenon, it's time to accept other success criteria", International Journal of Project Management, Vol. 17, pp. 337-342.

Axelson, M. and Richtner, A. (2017), "Organizational interfaces for knowledge integration in product development collaborations", Creativity and Innovation Management, Vol. 26 No. 4, pp. 418-429.

Bodas Freitas, I.M., Rossi, F. and Geuna, A. (2014), "Collaboration objectives and the location of the university partner: evidence from the Piedmont region in Italy", Papers in Regional Science, Wiley Blackwell, Vol. 93, pp. 203-226, November.

Bogers, M. and Horst, W. (2013), "Collaborative prototyping: cross-fertilization of knowledge in prototype-driven problem solving", Journal of Product Innovation Management, Vol. 31 No. 7, pp. 1-21.

Brown, S.L. and Eisenhardt, K.M. (1995), "Product development: past research, present findings and future directions", Academy of Management Review, Vol. 20 No. 2, pp. 343-378.

Bruneel, J., D'Este, P. and Saltera, A. (2010), "Investigating the factors that diminish the barriers to university-industry collaboration", Research Policy, Vol. 39 No. 7, pp. 858-868.

Cabigiosu, A. and Camuffo, A. (2012), "Beyond the mirroring hypothesis: product modula- rity and supply-relations in the air-conditioning industry", Organization Science, Vol. 23 No. 3, pp. 686-703.

Canonico, P. and Söderlund, J. (2010), "Getting control of multi-project organizations: combining contingent control mechanisms", International Journal of Project Management, Vol. 28, pp. 796-806.

Canonico, P., De Nito, E., Esposito, V., Martinez, M. and Pezzillo Iacono, M. (2017), "The adoption of knowledge integration mechanisms in an interdisciplinary research project", Management Research Review, Vol. 40 No. 5, pp. 604-622.

Canonico, P., Consiglio, S., De Nito, E., Esposito, V. and Pezzillo Iacono, M. (2018), "Dealing with knowledge in a product development setting: an empirical analysis in the automotive industry", Knowledge Management Research and Practice, Vol. 16 No. 1, pp. 126-133. 
Canonico, P., De Nito, E., Esposito, V., Pezzillo Iacono, M. and Consiglio, S. (2020), "Knowledge creation in the automotive industry: analysing obeya-oriented practices using the SECI model", Journal of Business Research, Vol. 112, pp. 450-457.

Carlile, P.R. and Rebentisch, E.S. (2003), "Into the black box: the knowledge transformation cycle", Management Science, Vol. 49 No. 9, pp. 1180-1195.

Christensen, P.H. (2003), Knowledge Sharing - Time Sensitiveness and Push-Pull Strategies in a Non-hype Organization, EGOS Colloquium, Copenhagen Business School, Copenhagen.

Cicmil, S. (2006), "Understanding project management practice through interpretative and critical research perspectives", Project Management Journal, Vol. 37 No. 2, pp. 27-37.

Collins, H.M. and Evans, R. (2007), Rethinking Expertise, University of Chicago Press, Chicago, IL.

Cunningham, J.A., Menter, M. and Young, C. (2017), "A review of qualitative case methods trends and themes used in technology transfer research", The Journal of Technology Transfer, Vol. 42 No. 4, pp. 923-956.

Czarniaswka, B. (2004), Narratives in Social Science Research, Sage, London.

de Rond, M. and Bouchikhi, H. (2004), "On the dialectics of strategic alliances”, Organization Science, Vol. 15, pp. 156-169.

De Meyer, A., Loch, C. and Pich, M. (2002), "Managing project uncertainty: from variation to chaos", Engineering Management Review, IEEE Engineering Management Review, Vol. 43 No. 3, p. 91.

Dubois, A. and Gadde, L. (2002), "The construction industry as a loosely coupled system: implications for productivity and innovation”, Construction Management and Economics, Vol. 20 No. 7, pp. 621-631.

Dyer, W.G. and Wilkins, A.L. (1991), "Better stories, not better constructs, to generate better theory: a rejoinder to Eisenhardt", Academy of Management Review, Vol. 16, pp. 613-619.

Eisenhardt, K.M. (1989), "Building theories from case study research", Academy of Management Review, Vol. 14 No. 4, pp. 532-550.

Engstrand, A.K. and Enberg, C. (2020), "The power in positionings: a foucauldian approach to knowledge integration processes", Management Learning, Vol. 51 No. 3, pp. 336-352.

Engwall, M. (2003), "No project is an island: linking projects to history and context", Research Policy, Vol. 32 No. 5, pp. $789-808$.

Evered, R. and Reis Louis, M. (2001), "Alternative perspectives in the organizational sciences: 'inquiry from the inside' and 'inquiry from the outside", Academy of Management Review, Vol. 6 No. 3, pp. 385-395.

Furlan, A., Cabigiosu, A. and Camuffo, A. (2014), "When the mirror gets misted up: modularity and technological change", Strategic Management Journal, Vol. 35 No. 6, pp. 789-807.

Giuliani, E. and Arza, V. (2009), "What drives the formation of 'valuable' university- industry linkages? Insights from the wine industry", Research Policy, Vol. 38 No. 6, pp. 906-921.

Grabher, G. (2004), “Temporary architectures of learning: knowledge governance in project ecologies”, Organizational Studies, Vol. 25 No. 9, pp. 1491-1514.

Graham, C.R. (2006), "Blended learning systems: definition, current trends, and future directions", in Bonk, C.J. and Graham, C.R. (Eds), Handbook of Blended Learning: Global Perspectives, Local Designs, Pfeiffer Publishing, San Francisco, pp. 3-21.

Hodgson, D. and Cicmil, S. (Eds), (2006), Making Projects Critical, Palgrave, New York, NY.

Kellogg, K.C., Orlikowski, W.J. and Yates, J. (2006), "Life in the trading zone: structuring coordination across boundaries in postbureaucratic, organizations", Organization Science, Vol. 17 No. 1, pp. 22-44.

Lainer-Vos, D. (2013), "Boundary objects, zones of indeterminacy, and the formation of Irish and Jewish transnational socio-financial networks", Organization Studies, Vol. 34 No. 4, pp. 515-532. 
Lenfle, S.J. and Söderlund, J. (2019), "Large-scale innovative projects as temporary trading zone: toward an interlanguage theory", Organization Studies, Vol. 40 No. 11, pp. 1713-1739.

Lindkvist, L. (2005), "Knowledge communities and knowledge collectivities: a typology of knowledge work in groups", Journal of Management Studies, Vol. 42 No. 6, pp. 1189-1210, September.

Lindkvist, L., Söderlund, J. and Tell, F. (1998), "Managing product development projects: on the significance of fountains and deadlines", Organization Studies, Vol. 19 No. 6, pp. 931-951.

Liyanage, C., Elhag, T., Ballal, T. and Li, Q. (2009), "Knowledge communication and translation - a knowledge transfer model", Journal of Knowledge Management, Vol. 13 No. 3, pp. 118-131.

Lundin, R.A. and Soderholm, A. (1995), "A theory of the temporary organization", Scandinavian Journal of Management, Vol. 11, pp. 437-455.

Meng, D., Li, X. and Rong, K. (2019), "Industry-to-university knowledge transfer in ecosystem-based academic entrepreneurship: case study of automotive dynamics and control group in Tsinghua university", Technological Forecasting and Social Change, Vol. 141, pp. 249-262.

Morandi, V. (2013), "The management of industry-university joint research projects: how do partners coordinate and control R\&D activities?", The Journal of Technology Transfer, April, Vol. 38 No. 2, pp. 69-92.

Mueller, P. (2006), "Exploring the knowledge filter: how entrepreneurship and university-industry relationships drive economic growth", Research Policy, Vol. 35 No. 10, pp. 1499-1508.

Perkmann, M. and Walsh, K. (2007), "University-industry relationships and open innovation: towards a research agenda", International Journal of Management Reviews, Vol. 9 No. 4, pp. 259-280.

Petrilli, S. (2003), "Translation and semiosis: introduction", in Petrilli, S. (Ed.), Translation, Rodopi, Amsterdam, New York, NY, pp. 17-37.

Rajalo, S. and Vadi, M. (2017), "University-industry innovation collaboration: reconceptualization", Technovation, Vols 62-63, pp. 42-54.

Rasiah, R. and Govindaraju, C. (2009), "University-industry R\&D collaboration in the automotive, biotechnology and electronics firms in Malaysia”, Seoul Journal of Economics, Vol. 22, pp. 529-550.

Rau, C., Neyer, A.K. and Möslein, K.M. (2012), "Innovation practices and their boundary-crossing mechanisms: a review and proposals for the future", Technology Analysis and Strategic Management, Vol. 24 No. 2, pp. 181-217.

Sandberg, J., Holmström, J., Napier, N. and Leven, P. (2015), "Balancing diversity in innovation networks", European Journal of Innovation Management, Vol. 18 No. 1, pp. 44-69.

Scandura, A. (2016), "University-industry collaboration and firms' R\&D effort", Research Policy, Vol. 45, pp. 1907-1922.

Schaeffer, V., Öcalan-Özel, S. and Pénin, J. (2020), "The complementarities between formal and informal channels of university-Industry knowledge transfer: a longitudinal approach", The Journal of Technology Transfer, Vol. 45, pp. 31-55.

Seaton, R.A.F. (2002), Knowledge Transfer'. Strategic Tools To Support Adaptive, Integrated Water Resource Management Under Changing Conditions At Catchment Scale - A Co-Evolutionary Approach, The AQUADAPT Project, Bedford.

Secundo, G., Del Vecchio, P., Simeone, L. and Schiuma, G. (2019a), "Creativity and stakeholders' engagement in open innovation: design for knowledge translation in technology-intensive enterprises", Journal of Business Research, Available online 7 March 2019, doi: 10.1016/j.jbusres. 2019.02.072.

Secundo, G., Ndou, V., Del Vecchio, P. and De Pascale, G. (2019b), "Knowledge management in entrepreneurial universities: a structured literature review and avenue for future research agenda", Management Decision, Vol. 57 No. 12, pp. 3226-3257.

Simeone, L., Secundo, G. and Schiuma, G. (2017), "Knowledge translation mechanisms in open innovation: the role of design in R\&D projects", Journal of Knowledge Management, Vol. 21 No. 6, pp. 1406-1429.
Knowledge translation in universities 
Simeone, L., Secundo, G. and Schiuma, G. (2018), "Arts and design as translational mechanisms for academic entrepreneurship: the metaLAB at Harvard case study", Journal of Business Research, Vol. 85, pp. 434-443.

Söderlund, J. (2011), "Pluralism in project management: navigating the crossroads of specialization and fragmentation", International Journal of Management Review, Vol. 13 No. 2, pp. 153-176.

Söderlund, J. and Tell, F. (2011), "The P-form corporation: contingencies, characteristics, and challenges", in Morris, P., Pinto, J. and Soderlund, J. (Eds), The Oxford Handbook of Project Management, Oxford University Press, Oxford.

Szulanski, G. (1996), "Exploring internal stickiness: impediments to the transfer of best practice within the firm", Strategic Management Journal, Vol. 17 Winter Special Issue, pp. 27-43.

Valentine, M.A. and Edmondson, A.C. (2015), "Team scaffolds: how meso-level structures enable role-based coordination in temporary groups", Organization Science, Vol. 26 No. 2, pp. 405-422.

Valio Dominguez Gonzalez, R. and Fernando Martins, M. (2014), "Mapping the organizational factors that support knowledge management in the Brazilian automotive industry", Journal of Knowledge Management, Vol. 18 No. 1, pp. 152-176.

Van Maanen, J., Sørensen, J.B. and Mitchell, T.R. (2007), "The interplay between theory and method”, The Academy of Management Review, Vol. 32 No. 4, pp. 1145-1154.

Yih-Tong Sun, P. and Scott, J.L. (2005), “An investigation of barriers to knowledge transfer”, Journal of Knowledge Management, Vol. 9 No. 2, pp. 75-90.

Yin, R.K. (1994), Case Study Research Design and Methods: Applied Social Research and Methods Series, 2nd ed, Sage, Thousand Oaks, CA. 
Appendix

\section{The interviews' structure}

Questionnaire sections

Main questions of each section

1. The overall organization of the project

\section{Organizational practices within the cross-boundary team} and costs? came about? critical points of each phase? outcome of these actions? project members?
(1) What were the main objectives of the project?

(2) What were the key elements of the project in terms of scheduling

(3) Can you tell me how the idea of developing a U-I collaboration

(4) In how many phases was the project articulated?

(5) Could you describe the main objectives, working methods and

(6) What were your main tasks and activities? What was the

(1) What were the main coordination mechanisms used among

(2) Could you describe an episode where there was a misunderstanding between researchers and managers? Can you describe a specific incident case? What actually happened? When and where did it happen? What would you have done differently if you could do it over again?

(3) Can you provide an example of a problem that you solved and how?

(4) How was the meeting space used? How frequently were formal or virtual meetings held to discuss new ideas or process upgrading?

(5) How was project management software used?

(1) What were the main tools to exchange data, information and knowledge between project members at different phases of the project?

(2) How were those tools actually used?

(3) What kind of knowledge did you need to work effectively? mechanisms and practices
Knowledge translation in universities

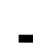


and organizational design. $\mathrm{PhD}$ in organization design and human resource management, University of

Molise, his research interests embrace the fields of knowledge management and innovation, organizational control in private and public sector, inter-organizational coordination mechanisms in private and public sectors.

Gianluigi Mangia is full professor of organization studies at University of Napoli Federico II, Italy and professor of public management and head of management, organization and human resources department at Scuola Nazionale dell'Amministrazione (National School of Administration), Italy. He is board member of EGOS (European Group of Organizational Studies). His research interests are around public organizations, power and resistance in organizations and organizational research methods.

For instructions on how to order reprints of this article, please visit our website: www.emeraldgrouppublishing.com/licensing/reprints.htm Or contact us for further details: permissions@emeraldinsight.com 